\title{
Increased concentrations of tumour necrosis factor in "cachectic" patients with severe chronic heart failure
}

John McMurray, Ibrahim Abdullah, Henry J Dargie, David Shapiro

\begin{abstract}
Objective-To ascertain whether patients with cardiac failure and reduced body weight ("cardiac cachexia") have increased circulating concentrations of tumour necrosis factor (cachectin).

Design-Patients with cardiac failure were prospectively identified as "cachectic" (body fat $<27 \%$ in men and $<29 \%$ in women measured by skinfold thickness callipers) or "non-cachectic". Tumour necrosis factor was assayed blind to patient group.

Setting-Cardiology unit in a tertiary referral centre.
\end{abstract}

Patients-26 consecutive patients (10 women) (mean age 61) admitted for investigation or treatment of chronic heart failure. All were in New York Heart Association class III or IV.

Results-In nine of the 16 cachectic patients the concentration of tumour necrosis factor was increased (mean (SEM) $74(20) \mathrm{pg} / \mathrm{ml}$ ) compared with one of the 10 "non-cachectic" patients (22 pg) $\mathrm{ml}, \mathrm{p}<0.001)$. Patients with a raised circulating concentration of tumour necrosis factor weighed significantly less $(55.6(3.5) \mathrm{kg})$ than those in whom the concentration of tumour necrosis factor was normal $(69.0(4 \cdot 1) \mathrm{kg})(\mathrm{p}=0.02)$.

Conclusions-Circulating concentrations of tumour necrosis factor were increased in a significant proportion of patients with chronic heart failure and low body weight. Tumour necrosis factor stimulates catabolism experimentally and it may be a factor in the weight loss seen in patients with "cardiac cachexia".

Department of Cardiology, Western Infirmary, Glasgow J McMurray I Abdullah

H J Dargie

Department of Pathological

Biochemistry,

Western Infirmary,

Glasgow

D Shapiro

Correspondence to

Dr John McMurray,

Department of Cardiology,

Department of Cardiology, Western In

G11 6NT.

Accepted for publication 23 May 1991
Some patients with chronic heart failure suffer generalised wasting referred to as "cardiac cachexia". Inadequate nutritional intake is not thought to be the major aetiological factor. ${ }^{12}$ Instead, it is suggested that cardiac cachexia is a catabolic state caused by the actions of a circulating factor. ${ }^{1}$ The same factor is considered to be responsible for the cachexia characterising malignant conditions. Recently, a circulating polypeptide causing catabolism and, in laboratory animals, cachexia has been identified and labelled tumour necrosis factor or "cachectin" ${ }^{3-5} \mathrm{We}$ have measured tumour necrosis factor concentrations and body fat content in patients with chronic heart failure.
Patients and methods

PATIENT POPULATION AND SKINFOLD MEASUREMENT

Twenty six consecutive patients aged 31-81 (mean (SEM) 61 (2) years), 10 of whom were female, admitted for investigation or treatment of chronic heart failure were studied with ethical approval and after giving informed consent. Chronic heart failure was secondary to coronary artery disease in 17, valve disease in seven, idiopathic dilated cardiomyopathy in one, and congenital heart disease in one. All patients were in New York Heart Association clinical class III or IV and were being treated with diuretics; most were receiving an angiotensin converting enzyme inhibitor and digoxin. Patients with significant concomitant disease (for example, infection, renal failure, pulmonary disease, thyroid disease, malignancy, collagen-vascular disease) were not studied. Once treatment had been optimised, subcutaneous fat was measuredthat is, in most cases immediately before discharge from hospital. We measured body fat content rather than body weight to avoid the potential complicating factor of residual fluid retention. ${ }^{6}$ Using callipers, a single practised observer measured biceps, triceps, infrascapular, and suprailiac skinfold thickness in quadruplicate (skinfolds over the lower part of the body were again avoided because retained fluid collects in dependent regions). The percentage body fat content was derived from the sum of the mean of each of these measurements and standard tables. ${ }^{7}$

Patients were prospectively grouped as "cachectic" (males <27\%, females $<29 \%$ body fat) and "non-cachectic" groups on the basis of body fat content; these percentage estimates were based on typical values for our non-chronic heart failure patients and published data from a local population.?

Venous blood was also collected from five healthy controls for measurement of tumour necrosis factor.

\section{BLOOD COLLECTION AND TUMOUR NECROSIS FACTOR ASSAY}

A $10 \mathrm{ml}$ sample of antecubital venous blood was taken into chilled potassium EDTA tubes from supine, resting subjects. These samples were immediately centrifuged at $4^{\circ} \mathrm{C}$ and the separated plasma stored at $-20^{\circ} \mathrm{C}$ until assay. All samples were assayed as a batch within two months of collection. Tumour necrosis factor was assayed without knowledge of which group patients belonged to, and whether the plasma was from a patient or 
Figure 1 Plasma concentrations of tumour necrosis factor $(\mathrm{pg} / \mathrm{ml})$ in cachectic and noncachectic patients with chronic heart failure. Lower limit of detection of assay $(15 \mathrm{pg} / \mathrm{ml})$; patients with concentrations below this are shown as open circles.

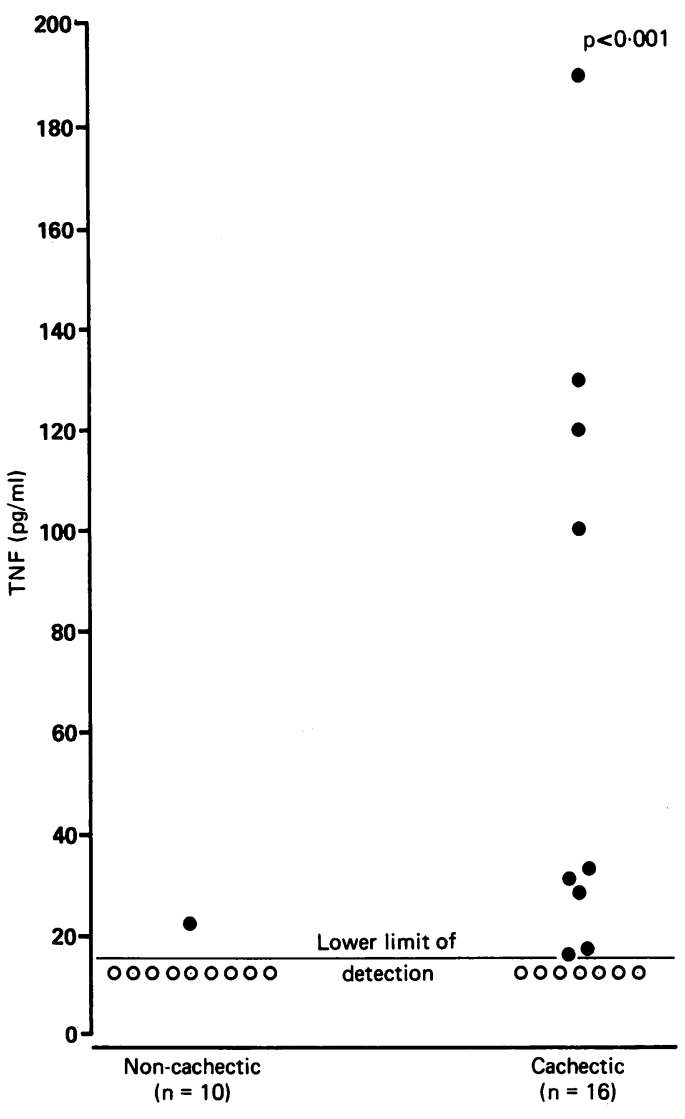

controls. Tumour necrosis factor was measured with a commercially available tumour necrosis factor $\alpha$-radioimmunoassay (IRE-Medgenix, Brussels, Belgium). ${ }^{8}$ Tumour necrosis factor should be undetectable $(<15 \mathrm{pg} / \mathrm{ml})$ in the plasma of healthy controls with this assay. The intra-assay and inter-assay coefficients of variation are $6.6 \%$ and $7 \cdot 5 \%$.

\section{STATISTICAL ANALYSIS}

The "non-cachectic" and "cachectic" groups of patients were compared by the $\chi^{2}$ test. Subsequently the "normal" and "raised" TNF groups were compared by independent $t$ tests. All values are given as mean (SEM).

\footnotetext{
Figure 2 Body mass ("weight", $\mathrm{kg}$ ) in patients with normal plasma concentrations of tumour concentrations of tumour those with raised concentrations (O).
}

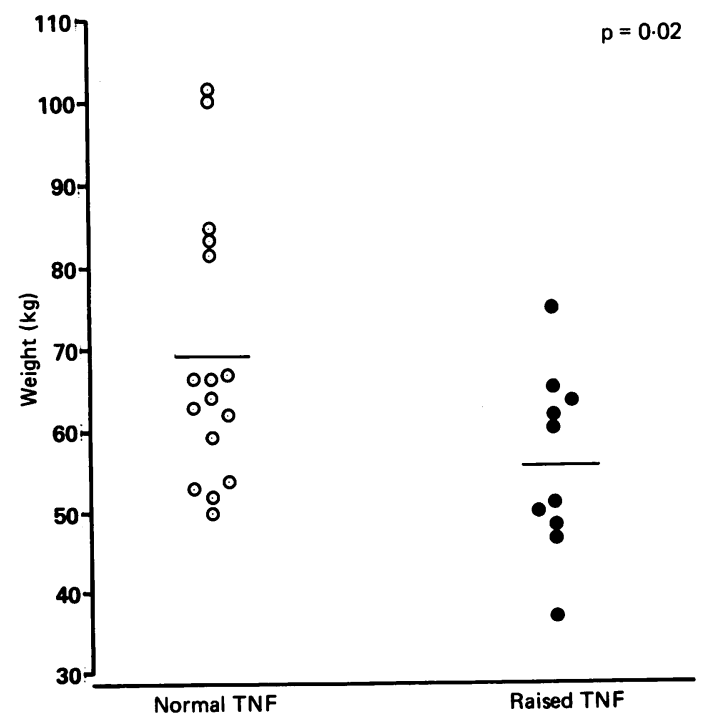

\section{Results}

Sixteen patients (11 male) were "cachectic" (mean (SEM) body fat content $21(1 \cdot 2) \%$ ). Of these, nine (chronic heart failure due to coronary disease in seven, valve disease in one, and congenital heart disease in one) had mixed circulating concentration $(>15 \mathrm{pg} / \mathrm{ml})$ of tumour necrosis factor (fig 1). Ten patients were not cachectic (body fat $31(1 \cdot 0) \%$ ). Only one patient (with chronic heart failure due to coronary artery disease) in this second group had raised circulating concentration of tumour necrosis factor $\left(\chi^{2}=14.8, \mathrm{p}<0.001\right)$.

Tumour necrosis factor was undetectable $(<15 \mathrm{pg} / \mathrm{ml})$ in frozen plasma from the five healthy controls.

Mean (SEM) body mass ("weight") was $69 \cdot 0$ $(4 \cdot 1) \mathrm{kg}$ in patients with undetectable tumour necrosis factor and $55.6(3.5) \mathrm{kg}$ in those with raised concentrations ( $p=0.02$ ) (fig 2). Body mass index (mass in $\mathrm{kg} /$ height $^{2}$ ) was $24.8(1.4)$ in patients with undetectable tumour necrosis factor and $20.3(1 \cdot 1)$ in those with raised concentrations ( $p=0.02$ ) (fig 3 ). Within the group of patients who were "cachectic" those with measurable tumour necrosis factor concentrations weighed $56.5(3.8) \mathrm{kg}$ and those without $66 \cdot 0(5 \cdot 1)$.

\section{Discussion}

One of the many effects of tumour necrosis factor is to cause cachexia. Our findings showed that reduced body fat content in chronic heart failure was associated with raised concentrations of tumour necrosis factor and suggested that wasting in chronic heart failure may be due to the sustained effect of this polypeptide. Our results accord with those of a recent study in which patients with chronic heart failure were found to have higher concentrations of tumour necrosis factor, measured by bioassay, than controls. In that study the patients with the highest concentrations of tumour necrosis factor had lower body weights. ${ }^{9}$ In the present study, a similar observation was made and body

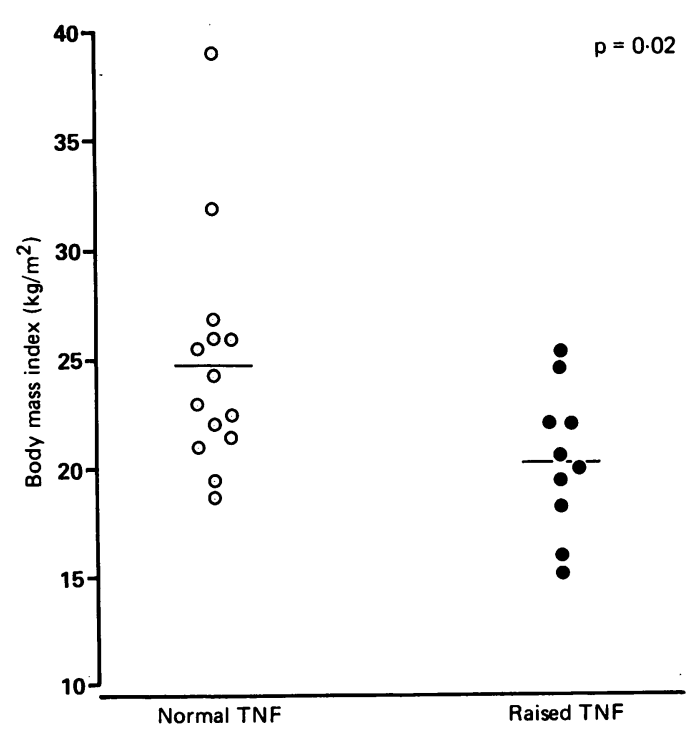

Figure 3 Body mass index (weight/height ${ }^{2}$ ) in patients with normal plasma concentrations of tumour necrosis factor $(\bigcirc)$ and those with raised concentrations $(0)$. 
mass index was also found to be decreased. Weight loss in other conditions, such as acquired immunodeficiency syndrome, chronic parasitic infection, and malignancy, has also been related to increased tumour necrosis factor concentrations. ${ }^{10-13}$ Seven patients who were "cachectic", however, did not have raised concentrations of tumour necrosis factor. Why some wasted patients had high concentrations and others did not is unclear. Those "cachectic" patients who did have high tumour necrosis factor concentrations tended to weigh less than "cachectic" patients with normal concentrations, suggesting the circulating peptide is only increased in the most advanced states of cardiac cachexia syndrome. A similar pattern has been noted in other disease states. For example, in human immunodeficiency virus infection, only patients with full-blown acquired immunodeficiency syndrome have significantly raised concentrations of tumour necrosis factor (up to $200 \mathrm{pg} / \mathrm{ml}$ ); those with acquired immunodeficiency syndrome related complex usually have normal cachectin concentrations. ${ }^{13}$. This may suggest that enhanced tumour necrosis factor activity, undetectable by existing assays, is present in the early course of cachectic illnesses or that these wasting syndromes are multifactorial with other factors leading to weight loss in the early stages.

Cardiac cachexia is debilitating, leading eventually to severe skeletal muscle wasting and consequent immobility; it is also associated with a poor prognosis. ${ }^{1}$ Recently, oxpentifylline has been reported to reduce the production of tumour necrosis factor in vitro and in vivo in healthy human volunteers. ${ }^{1415}$ This drug may offer the prospect of pharmacological intervention in cardiac cachexia. Fish oils too have been shown to suppress concentrations of tumour necrosis factor in humans, suggesting yet another therapeutic approach. ${ }^{16}$ Corticosteroids, which suppress tumour necrosis factor production, or anti-tumour necrosis factor antibodies might also be of benefit in chronic heart failure patients with progressive wasting. ${ }^{1718}$

Tumour necrosis factor has additional biological actions that may be disadvantageous in chronic heart failure. Tumour necrosis factor can promote intravascular coagulation, stimulate leucocyte adhesion and activation, and induce anaemia. ${ }^{41419}$ Tumour necrosis factor is also reported to depress myocardial contractility, alter muscle membrane potential, lower blood pressure, and precipitate pulmonary oedema. ${ }^{20-22}$ Anti-tumour necrosis factor interventions might therefore have other potentially beneficial effects in chronic heart failure.

$\mathrm{J}$ McMurray is a British Heart Foundation Intermediate Research Fellow.

1 Ansari A. Syndromes of cardiac cachexia and the cachectic heart: current perspective. Prog Cardiovasc Dis 1987;30 45-60.

2 Morrison WL, Edwards RHT. Cardiac cachexia. BMJ 1991;302:301-2.

3 Beutler B, Cerami A. Cachectin and tumour necrosis factor as two sides of the same biological coin. Nature 1986; 320:584-8.

4 Evans RD, Argiles JM, Williamson DH. Metabolic effects of tumour necrosis factor- $\alpha$ (cachectin) and interleukin-1. tumour necrosis factor-

5 Starnes HF, Warren RS, Jeevanandam M, Gabiolove JL, Larchian W, Oettgen HF, et al. Tumour necrosis factor and the acute metabolic response to tissue injury in man J Clin Invest 1988;82:1321-5.

6 Blackburn GL, Harvey KB. Nutritional assessment as a routine in clinical medicine. Postgrad Med 1982;71:46-63.

7 Durnin JVGA, Womersley J. Bodyfat assessed from total body density and its estimation from skinfold thickness: measurements on 481 men and women aged from 16-72 years. Br J Nutr 1974;32:77-97.

8 Leroux-Roels G, Offner F, Phillippe J, Vermuelen A. Influence of blood collecting systems on concentrations of tumour necrosis factor in serum and plasma. Clin Chem 1988;11:2373-4.

9 Levine B, Kalman J, Mayer L, Fillit HM, Packer M Elevated circulating levels of tumour necrosis factor in severe chronic heart failure. N Engl J Med 1990;323: in severe

10 Kern P, Hemmer CJ, van Damme J, Gruss HJ, Dietrich M. Elevated tumor necrosis factor alpha and interleukin-G serum levels as markers for complicated Plasmodium falciparum malaria. Am J Med 1986;2:1364-5.

11 Balkwill F, Burke F, Talbot D, Tavernier J, Osborne R, Naylor $\mathbf{S}$, et al. Evidence for tumour necrosis factor cachectin production in cancer. Lancet 1987;ii: 1229-32.

12 Scuderi P, Lam KS, Ryan KJ, Petersen E, Sterling KE Finley PR, et al. Raised serum levels of tumour necrosis factor in parasitic infections. Lancet 1986;ii:1364-5.

13 Lahdevirta J, Maury CPJ, Teppo A-M, Repo H. Elevated levels of circulating cachectin/tumour necrosis factor in patients with acquired immunodeficiency syndrome. $\mathrm{Am} \mathrm{J}$ Med 1988;85:289-91.

14 Zabel P, Walter DT, Schonharting MM, Schade UF Oxpentifylline in endotoxaemia. Lancet 1989;ii:1474-7.

15 Waage A, Sorensen M, Stordal B. Differential effect of oxpentifylline on tumour necrosis factor and interleukin 6 production. Lancet 1990;i:542-3.

16 Endres S, Ghorbani R, Kelley VE, Georgilis K, Lonnemann $\mathrm{G}$, van der Meer JW, et al. The effect of dietary supplementation with $n-3$ polyunsaturated fatty acids on the synthesis of interleukin -1 and tumor necrosis factor by mono nuclear cells. $N$ Engl J Med 1989;320:265-71.

17 Tracey KJ, Vlassara H, Cerami A. Cachectin/Tumour necrosis factor. Lancet 1989;i:1122-6.

18 Beutler B, Milsark IW, Cerami A. Passive immunisation against cachectin/tumour necrosis factor protects mice from the lethal effect of endotoxin. Science 1985;229: 869-71.

19 van der Poll T, Buller HR, tenCate $\mathrm{H}$, Wortel $\mathrm{CH}$, Bauer $\mathrm{KA}$, van Deventer SJH, et al. Activation of coagulation after administration of tumour necrosis factor to normal after administration of tumour necrosis fact.

20 Hocking DC, Phillips PG, Ferro TJ, Johnson A. Mechanisms of pulmonary oedema induced by tumour necrosis isms of pulmonary oedema induced

21 Tracey KJ, Lowry SF, Beutler B, Cerami A, Albert JD, Shires GT. Cachectin/tumour necrosis factor mediates changes of skeletal muscle plasma membrane potential. J Exp Med 1986;164:1368-73.

22 Cunnion RE, Parillo JE. Myocardial dysfunction in sepsis. Chest 1989;95:941-5. 